\title{
European Union Law and the Seabed
}

\author{
Finn Arnesen, Rosa Greaves, and Alla Pozdnakova
}

The European Union (EU) is a supranational organization established under international law. Nevertheless, over several decades, it has evolved into a suis generis international entity with its own legal order, significant competences and an effective enforcement mechanism. The Court of Justice of the European Union (CJEU), which under the Treaty has exclusive jurisdiction to interpret EU law and to review the legality of any EU secondary legislation, ${ }^{1}$ has emphasised the unique nature of the EU. ${ }^{2}$ The EU Member States did not delegate but transferred some sovereign rights to the EU meaning that only the EU has competence to act, either internally or externally, in a number of fields of activity. Furthermore, the transfer of sovereignty has not only occurred by expressed provision in the EU Treaties but also by the EU adopting extensive secondary legislation and thus occupying the field. ${ }^{3}$ This latter process means that for some activities, the initial shared competence to act has been replaced by exclusive EU competence.

In this chapter the focus is on the extent to which the EU has competence to regulate the seabed under the sovereign jurisdiction of the EU Member States and the manner in which the competence has been exercised. The chapter will explain first the extent of the EU's competence in respect of the relevant seabed (Section 2). Then, the chapter will, by way of illustration of the level of policy and legislative activity, consider two areas affecting the seabed: the EU's policy in respect of seabed mining and the application of EU environmental protection and liability legislation to the seabed (Section 3). In neither area has there been EU legislation adopted specifically in respect of the seabed. However, several policy papers have been published by the European Commission on seabed mining which demonstrates the Commission's intention for the EU to be an

1 Article 263 TFEU.

2 E.g. Van Gen den Loos, 26/62 [1963] ECR 1.

3 When the EU and the EU Member States share a competence, the latter lose their 'competence' (power to take decisions) when the EU decides to regulate in that area. The EU is said to 'occupy the field' meaning that the EU Member States no longer have the right to legislate in the covered area. Case 22/70 Commission v Council (ERTA Case) ECLI:EU:C:1971:32. 
active player in exploiting the seabed such as deep seabed mining. Similarly, current environmental protection legislative measures can be interpreted so as to extend their scope to the seabed. The last part of the chapter will provide some concluding observations (Section 4).

\section{EU Competences in Respect of the Seabed}

According to Article 5 of the Treaty on European Union (TEU), the EU competences are governed by the principle of conferral. This has two implications worth noticing in the context of the issues discussed in this chapter. First, the EU may only act within the limits conferred upon it by the TEU or the Treaty on the Functioning of the European Union (TFEU). Secondly, these competences may only be used to achieve the objectives set out in those treaties. Thus, competences not transferred to the EU, remain with the Member States. Competences conferred, may either become an exclusive EU competence, or a competence shared with the Member States. ${ }^{4}$ In matters concerning the use of the seabed, the competence is shared - with a possible caveat for measures affecting the use of the seabed taken under the common fisheries policy. However, the EU does not have competence relating to the continental shelf and the seabed unless the Member States have such competence under public international law.

The TEU and TFEU are - for the time being - a last step in the development of what is now known as the European Union. Today the competence conferred on the EU to regulate matters pertaining to the market place is supplemented by TFEU part Three, Titles XX and XXI - on environment and energy respectively.

In order to comprehend fully the impact of EU law on matters pertaining to the use, and non-use, of the seabed, one has to acknowledge the effects of the general provisions of the TFEU on the four freedoms, i.e. free movement of goods, services people and capital, competition between undertakings and state aid on activities relating to the seabed. These effects are, to the extent EU law is applicable, independent of any legislative acts adopted by the EU addressing seabed use.

Article 191 TFEU provides that EU policy on the environment shall contribute to the pursuit of four objectives. Among these we find traditional environmental aims such as the preservation, protection and improvement of

4 Articles 2 to 6 TFEU. 
the quality of the environment, but also prudent and rational utilization of natural resources. Article 192 TFEU provides the legal basis for legislative acts implementing EU's policy on the environment. These measures are to be adopted by majority voting according to the ordinary legislative procedure provided for in Article 114 TFEU. However, according to Article 192 (2) TFEU, some decisions nevertheless require unanimity. Among these are measures affecting 'land use' and measures 'significantly affecting a Member State's choice between different energy sources'. Whether 'land use' also cover use of the seabed, may be open to debate.

Article 194 provides for an EU policy on energy, and a legal basis for measures implementing this policy. The measures taken according to Article 194 TFEU may, 'without prejudice to Article 192(2), however not affect a Member State's right to determine the conditions for exploiting its energy resources, its choice between different energy resources and its general structure of energy supply.

As a legal topic, the EU and the use of the seabed have two dimensions. One dimension being the external, i.e. issues pertaining to the powers of EU institutions in interaction with third states - both within the framework of conventions to which EU is a party, like the UN Convention on the Law of the Sea (UNCLOS), and in relation to conventions where only (some) of the Member States are parties. As a matter of EU law, the EU has exclusive competence in certain areas covered by the Convention, and shared competence in others. Pursuant to Article 5(1) of Annex IX to the Convention, a declaration specifying these areas has been given.

The other dimension is the internal dimension, i.e. issues pertaining to EU competence to regulate activities taking place outside the territories of the Member States. This internal dimension gives rise to two discussions. The first being to what extent EU law applies to measures taken by Member States that relate to activities taking place outside their territory but under their jurisdiction. The other being to what extent the EU has competence to oblige the Member States to undertake certain activities, for instance explore for natural resources, make certain uses of the seabed, lay (or allow) cables and pipelines, etc.

In public international law, terms like 'territory', 'continental shelf', and 'economic zone' are used to define the sovereignty and jurisdiction of states. Turning to Article $5^{2} \mathrm{TEU}$, we see that this provision proclaims that the EU Treaties apply to the Member States, and that the territorial scope of the treaties is specified in Article 355 TFEU. Article 355 TFEU does however not shed much light on the application of EU law outside the territories of the Member 
States. It is nevertheless established through CJEU case-law that EU law applies where Member States have sovereign powers. This can be illustrated by Salemink, ${ }^{5}$ where the CJEU held:

Since a Member State has sovereignty over the continental shelf adjacent to it - albeit functional and limited sovereignty (see, to that effect, Case C-111/05 Aktiebolaget NN [2007] ECR I-2697, paragraph 59) - work carried out on fixed or floating installations positioned on the continental shelf, in the context of the prospecting and/or exploitation of natural resources, is to be regarded as work carried out in the territory of that State for the purposes of applying EU law (see, to that effect, Case C-37/oo Weber [2002] ECR I-2013, paragraph 36, and Case C-6/04 Commission v United Kingdom [2005] ECR I-9017, paragraph 117).

A Member State which takes advantage of the economic rights to prospect and/or exploit natural resources on that part of the continental shelf which is adjacent to it cannot avoid the application of the EU law provisions designed to ensure the freedom of movement of persons working on such installations. ${ }^{6}$

The case concerned the application of EU law on the free movement of persons, but the same applies to other fields of EU law, national sovereignty carries EU law on its back, not unlike the snail carries its shell. Thus, the applicability of EU law to issues relating to geographical areas outside the territories of the Member States has to be decided on the basis of an interpretation of the relevant EU legal act and the Member States' jurisdiction over the issue and the area, and then made subject to possible functional caveats.

As a matter of comparison, under the Agreement on the European Economic Area (EEA Agreement), this may be different, as Article $126 \mathrm{EEA}$ uses the term 'territory', and expressly proclaims that the agreement is applicable to territories of the EFTA States and the territories to which EU law applies. Thus, the position of Norway is that the EEA Agreement, and thus EEA law, does not apply to matters concerning the Norwegian continental shelf, as these do not take place on Norwegian territory. The EFTA Surveillance Authority (ESA) has voiced a different opinion. ${ }^{7}$

5 Case C-347/10, ECLI:EU:C:2012:17.

6 Case C-347/10 Salemink, paras 35 and 36.

7 Finn Arnesen, comments on Art. 126 EEA, in F. Arnesen, H.H. Fredriksen, H.P. Graver, O. Mestad and C. Vedder (eds.) Agreement on the European Economic Area - A Commentary, Nomos Verlagsgesellschaft, Baden-Baden 2018. The EEA Agreement and activities off-shore, SIMPLY [2010] p. 17. 
Whether the EU may adopt measures obliging the Member States to undertake certain activities, depends on the powers conferred on the EU by the Member States, and the prerequisites for executing those powers. As far as environmental issues are concerned, we have seen that measures affecting land use require unanimity, as do measures affecting a Member State's choice between energy resources, ${ }^{8}$ while EU measures shall not affect a Member State's right to determine the conditions for exploiting its energy resources. ${ }^{9}$

\section{The Exercise of EU Competences with Respect of the Seabed}

Two areas in respect of the seabed have been selected to illustrate the extent of the EU's competence to regulate the seabed and the manner in which it seeks to play a significant role internationally. Seabed mining, meaning the extraction of minerals ${ }^{10}$ from the seabed from a depth of more than 200 metres, is an economic activity at an embryonic stage but with immense potential to develop into a major industrial activity. It is therefore not surprising that the EU has expressed interest in playing a major role in shaping its governance." It is therefore appropriate to explore how the EU will achieve its objective (Section 3.1). Environmental protection and liability, on the other hand, is an area where the EU has already adopted a number of significant legal instruments, some of which have had impact on marine and maritime activities. In this section of the chapter, the extent to which the legislation on environmental protection and liability applies to the seabed will also be considered (Section 3.2).

\subsection{Seabed Mining (Minerals)}

The first thing to be remembered about seabed mining is that it has not yet taken place anywhere in the world on a commercial basis. However, the idea of mining the seabed for the extraction of minerals and rare earth elements is not

8 Article $192 \mathrm{TFEU}$.

$9 \quad$ Article 194(2) second paragraph.

10 Extraction of marine aggregates such as sand and gravel are excluded. Minerals are to be understood as raw materials found on or under the seabed.

11 Joint Communication to the European Parliament, the Council, the European Economic and Social Committee and the Committee of the Regions, entitled 'International ocean governance: an agenda for the future of our oceans' JOIN(2016) 49 final of 10 November 2016. 
new. The main reasons that have prevented the growth of this new industry are environmental issues and costs. ${ }^{12}$

As far as the EU is concerned seabed mining is an economic activity with huge potential for EU undertakings engaged in seabed mining activities such as technology providers who are rapidly expanding the capabilities of underwater technology. ${ }^{13}$ Thus the EU, within the limits of its competence as discussed in Section 2, is certainly ensuring that it has a role to play in shaping this industry as part of its general industrial policy. The European Commission is thus engaged in commissioning a variety of studies and providing funding for projects ${ }^{14}$ that will reduce knowledge gaps associated with seabed mining as well as identifying the benefits and drawbacks of seabed mining operations. In addition, the Commission has issued a number of policy documents, 'communications' with relevance to seabed mining. ${ }^{15}$

UNCLOS, to which both the EU and the EU Member States are parties, provides that each coastal State may regulate seabed mining in maritime areas under its national jurisdiction but it does not provide any legal framework as to how the task should be exercised. As far as seabed mining is concerned beyond the maritime areas under the jurisdiction of States, the so-called 'Area', UNCLOS, supplemented by Part XI Implementation Agreement, provides an incomplete legal framework for seabed mining. ${ }^{16}$

Although UNCLOS governs the use of the oceans and their resources, sectoral activities such as seabed mining are the responsibility of an international institution, the International Seabed Authority (ISA). ${ }^{17}$ In its Joint Communication

12 For example, a Canadian company, Nautilus Minerals, was granted a 20 year lease by the Papua New Guinean government to mine offshore but soon terminated their project due mainly to costs.

13 E.g. vacuum pumps and remotely operated vehicles.

14 E.g. Managing Impacts of Deep-seA reSource exploitation (MIDAs) project - a multidisciplinary research programme investigating the environmental impacts of extracting mineral and energy resources from the deep-sea environment. It is funded under the European Commission's Framework 7 programme and was started in 2013 for a period of 3 years <http://www.eu-midas.net/>; Study on deep sea mining <https://webgate .ec.europa.eu/maritimeforum/en/node/3617 >; Blue Mining project also funded under the Framework 7 programme $<$ http://www.bluemining.eu $>$.

15 E.g. Communication of the Commission: Blue Growth opportunities for marine and maritime sustainable growth $\operatorname{COM}(2012) 49$ final.

16 For a discussion of the international legal framework, see Chapter 7 of this book, J. Dingwall, 'Commercial Mining Activities in the Deep Seabed Beyond National Jurisdiction: The International Legal Framework'.

Ibid, for details of competences, powers and actions. 
on international ocean governance published in November 2016,18 the European Commission stresses that the current international framework is not adequate to make sure that management of the oceans is sustained. The Communication highlights that ISA has not yet adopted a mining code setting out rules and procedures to govern seabed mining. ${ }^{19}$ In addition, the Commission expresses concern at the lack of coordination between the various international organisations with sector specific responsibilities for the oceans. ${ }^{20}$

The importance of this Commission document should not be underestimated. The strategy, namely the publication of policy papers identifying inefficiencies in international frameworks and setting out a number of proposed actions is not an uncommon practice before the Commission goes on, at a future date, to make legislative proposals for action and promote their adoption by the European Council and the European Parliament. Indeed in this Joint Communication, the Commission emphasises its experience of ocean management ${ }^{21}$ to claim that the $\mathrm{EU}$ is 'well placed to shape international ocean governance. ${ }^{22}$

The Joint Communication specifies a number of actions that are to be initiated. In the context of seabed mining the relevant action (Action 1) relates to filing the gaps in the international ocean governance framework. The Commission commits to producing guidance 'on the exploration and exploitation of natural resources on the seabed areas under national jurisdiction, [in order] to assist coastal Member States to respect their duty under UNCLOS to protect and preserve the marine environment. ${ }^{23}$

As to the internal dimension, it is clear from CJEU case $\operatorname{law}^{24}$ that EU law applies to maritime areas over which EU Member States have jurisdiction. Given that UNCLOS provides that each coastal State may regulate seabed mining in maritime areas under its national jurisdiction then it follows that the national law of the relevant EU Member States and EU law apply to seabed mining operations within those maritime areas. It is also clear that no EU

18 Joint Communication to the European Parliament, the Council, the European Economic and Social Committee and the Committee of the Regions entitled 'International ocean governance: an agenda for the future of our oceans, JOIN(2016)49 final.

19 Such a code is being prepared.

20 (n18), p. 3.

21 Marine Strategy Framework Directive; Maritime Spatial Planning Directive; reformed Common Fisheries Policy; and its maritime transport policy.

22 (n18), p. 4.

23 (n18), p. 6.

24 Case 61/77 Commission v Ireland [1978] 417, paras 45 to 51 . 
legislation has been adopted specifically to govern exploration or extraction and exploitation of seabed mining either within maritime areas under the national jurisdiction of EU Member States ${ }^{25}$ or beyond. Thus, until the EU occupies this field by adopting specific legislation, the EU Member States have competence to act.

There is no doubt that the EU legislative measures, which are the most likely to have a potential significant impact on seabed mining activities, are the directives that have been adopted to protect the environment. ${ }^{26} \mathrm{~A}$ discussion of the application of these directives to seabed mining will be provided in the second section of this part of the chapter. However, given the fact that seabed mining is an economic activity, it is highly likely that a whole range of other secondary legislation, which has been adopted to regulate market operators in their economic activities, will also be applicable. There are, for example, EU directives which impose reporting obligations on undertakings, such as the obligation on large and listed companies to publish information on payments made to governments. ${ }^{27}$

One major concern that is worth noting is the following. There are no international standards for seabed mining at present so the coastal states may adopt their own legislation accordingly which may give rise to a risk of different standards being applied. If this were to happen in respect of EU Member States it is highly likely that the EU would act under the competence granted under Article $114 \mathrm{TFEU}^{28}$ and adopt legislation on the basis that harmonisation of national laws in respect of seabed mining was necessary to safeguard the EU's internal market objective. An alternative softer approach may be to promote the adoption of EU standards for seabed mining operations. This could, of course, also be problematic as you could have a different standard for the Area (ISA's responsibility) from that being applied to maritime areas under the jurisdiction of EU Member States for the same activity.

By way of summary the EU's position as far as its competence and policy on seabed mining is concerned is reasonably clear. EU law applies to maritime areas under the jurisdiction of EU Member States. Seabed mining is an

25 These include not only 'the territorial sea' (i.e. 12 nautical miles from the baseline) but also the exclusive economic zone, the 'EEZ' (up to 200 nautical miles) and adjacent 'continental shelf' which comprises the seabed and subsoil of the submarine areas beyond the territorial sea.

26 See the 2015 Study to investigate the state of knowledge of deep sea mining by ECORYS and MRAS - <https://webgate.ec.europa.eu/maritimeforum/en/node/373>.

27 Accounting Directive, Directive 2013/34, OJ 2013 L182, on annual financial statements.

28 This Treaty provision provides the legal base for the adoption of EU approximation measures whose objective is the establishment and functioning of the internal market. 
economic activity and will be treated like any other economic activity within the internal market. Where necessary, the European Commission is likely to propose legislation to ensure that the seabed mining activity, within the jurisdiction of the EU Member States, is regulated and thus to ensure that the objectives of the internal market are achieved: no discrimination; free movement of goods, services people and capital, competition between undertakings and state aid.

Given that the EU and the EU Member States are party to UNCLOS and UNCLOS is an integral part of the EU legal order, the EU will respect international norms adopted under its auspices. Thus, as far as seabed mining activities in the Area are concerned, any activity will be governed by international law and the EU Member States will be encouraged by the European Commission to adopt the necessary laws under UNCLOS to protect and preserve the marine environment.

Nevertheless, in its latest Communication, ${ }^{29}$ the European Commission has made it clear that it will not wait for ISA's mining code before adopting its own guidelines to regulate seabed mining activities in maritime areas under the national jurisdiction of the EU Member States.

\subsection{Environmental Regulation of Seabed Activities}

In the discussion above we have examined EU competence to regulate activities on the seabed and concluded that this competence is, generally, shared but to-date has not been exercised. However, by contrast to measures related to the seabed mining, several environmental measures relevant to the offshore sector have been adopted by the EU.

This section focuses on how the EU has exercised its competence to protect the environment from the pollution caused by seabed activities of the Member States and considers whether EU measures are adequate to address the environmental issues posed by the new uses of the seabed.

It is debatable whether environmental protection in the offshore sector should be achieved by the EU rather than by the Member States. Even in the absence of EU action some steps have been taken by EU Member States at national level to counteract risks of environmental damage which may result from offshore operations. In particular, this is achieved through a system of authorization of offshore activities, which require undertakings, amongst other obligations, to obtain licences and meet other requirements (as the case may be) prior to starting offshore operations.

29 Above (n18). 
Moreover, the State's duty to protect the environment from the pollution caused by offshore activities is set out in the international instruments. First, a general duty is imposed in UNCLOS ${ }^{30}$ on States to prevent, reduce and control pollution of the marine environment arising from or in connection with seabed activities subject to their jurisdiction. Secondly, two regional agreements, the Convention for the Protection of the Marine Environment of the North-East Atlantic (the OSPAR Convention) ${ }^{31}$ and the Offshore Protocol of Barcelona Convention, ${ }^{32}$ do regulate important environmental aspects of offshore activities in the North East Atlantic and in the Mediterranean Sea. By virtue of EU's accession to these agreements, their provisions are part of the EU's legal order and, therefore, binding on the EU and its Member States.

It is outside the scope of this chapter to give a detailed account of the national and international environmental safety rules applicable to the activities on the seabed within Member States' jurisdiction. It is sufficient to submit briefly that, in spite of the existence of some international and national safety regulations in this sector, important gaps and inconsistencies still exist. Importantly, the national approaches to risk management and safety culture in the offshore sector have been found to vary significantly among the EU Member States. ${ }^{33}$ Given the gaps and diversity of approach to risk management, the EU may play an important role in contributing to the improvement in the level of protection of the seabed environment across the EU by adopting secondary legislation harmonizing the national approaches and thus ensure that a minimum standard of safety applies in all EU Member States active in the offshore sector.

As mentioned previously, Article 191(2) TFEU sets out the following principles for EU environmental action which are also highly relevant to the offshore sector: the precautionary principle; the principle that preventive action should

30 Article 208 UnCLOS. Council Decision 98/392/EC, OJ 1998 L179/1, of 23 March 1998 concerning the conclusion by the European Community of the United Nations Convention of 10 December 1982 on the Law of the Sea; the Agreement of 28 July 1994 relating to the implementation of Part XI thereof.

31 Council Decision 98/249/EC, OJ 1998 L104/1, of 7 October 1997 on the conclusion of the Convention for the protection of the marine environment of the north-east Atlantic.

32 Council Decision 2013/5/EU, OJ 2013 L4/13, of 17 December 2012 on the accession of the European Union to the Protocol for the Protection of the Mediterranean Sea against pollution resulting from exploration and exploitation of the continental shelf and the seabed and its subsoil.

33 SEC(2011) 1293 final, Commission Staff Working Paper. Impact Assessment Accompanying the document Proposal for the Regulation of the European Parliament and of the Council on safety of offshore oil and gas prospection, exploration and production activities, $\operatorname{COM}(2011) 688$ final. 
be taken; the principle that rectification of environmental damage at source is a priority; and the principle that the polluter should pay. If not all, then at least some of these principles have counterparts in international law, and therefore are relevant (although not necessarily binding) on EU Member States. ${ }^{34}$ However, the scope and contents of the principles (and their legal effect) is unclear in international law and EU Member States' approaches to them may differ significantly. ${ }^{35} \mathrm{EU}$ measures may, therefore, provide precise content and effect to the principles.

A Common EU Action must be able to raise to an acceptable level the safety legislation of those EU Member States which fall below and to overcome divergences in the national approaches to the offshore safety culture and pollution preparedness among Member States. It is also important when drawing up a Common Action to take into consideration the probable transboundary impact of an offshore pollution incident in Member States' waters.

These ambitious aims can only be achieved if EU measures are adopted in a timely and effective manner which may not necessarily be possible due to the legislative procedures described in Section II above. ${ }^{36}$ Furthermore, the obligations set out in the EU legislative measure should be formulated precisely and in sufficient detail. ${ }^{37}$ Thus, in making the choice between a regulation or a directive the European Commission is likely to prefer a regulation which is directly applicable ${ }^{38}$ and does not require (or allow) any national implementing measures, while at the same time giving a possibility for EU legislators to envisage adoption of implementing legal acts where necessary.

However, the objectives of Article $191 \mathrm{TFEU}$ are to be achieved by the adoption of harmonisation measures which means directives. Directives, by contrast to regulations, do not have direct effect and are only binding upon the EU Member States as to the result to be achieved, leaving to the national authorities the choice of form and methods of implementation. ${ }^{39}$ Accordingly,

34 See generally Nicolas de Sadeleer. Environmental Principles: From Political Slogans to Legal Rules, OUP, 2002, p. 91 et seq. Note that Article 191 is only binding on EU, not Member States.

35 See, e.g., Daniel Bodansky, 'Deconstructing the Precautionary Principle,' at pp. 381-391 in D.D. Caron and H.N. Scheiber (eds), Bringing New Law to Ocean Waters, 2004, Koninklijke Brill N.V.

$36 \quad$ Kramer (2015), p. 55 .

37 Ibid.

38 Direct applicability means that the EU regulation is incorporated into of the national legal orders of the EU Member States on publication in the EU's Official Journal. Regulations also have 'direct effect' meaning that individuals can rely on provisions of EU regulations before national courts.

Article 288(3) TFEU. 
the obligations and responsibilities of the offshore actors provided in the relevant EU directives and examined in more detail below must be properly transposed in the national laws of Member States before they become applicable to these actors. ${ }^{40}$

Over time, the EU adopted several secondary legislative measures which give effect to the principles laid down in Article 191 TFEU in respect of the protection of the marine environment. It is important to note that EU's provisions regulating environmental issues in the offshore sector are found in a range of directives. Some of these measures have general application and regulate all sectors, including the offshore sector, unless expressly excluded from their scope. The relevant directives ${ }^{41}$ are: the Marine Strategy Framework Directive; ${ }^{42}$ the Environmental Liability Directive; ${ }^{43}$ the Environmental Impact Assessment Directive; ${ }^{44}$ Directive on the conservation of natural habitats and of wild fauna and flora (Habitats Directive). ${ }^{45}$

Initially, EU legislation adopted specifically for the offshore sector addressed only access to the markets of the EU Member States. For example, the Prospection, Exploration and Production of Hydrocarbon Directive $(1994)^{46}$ mentions briefly the protection of the environment and biological resources as one of the grounds for a Member State to impose conditions and requirements on the activities regulated by the Directive. ${ }^{47}$

This Directive does not set out any specific criteria for Member States' decision to rely on the protection of the environment. However, the authorization

$40 \quad$ Above (n36), p. 55 .

41 It is outside the scope of this section to address all these general directives in detail.

42 Directive 2008/56/EC, OJ 2008 L164/19, of the European Parliament and of the Council of 17 June 2008 establishing a framework for community action in the field of marine environmental policy (Marine Strategy Framework Directive).

43 Directive 2004/35/CE, OJ 2004 L143/56, of the European Parliament and of the Council of 21 April 2004 on environmental liability with regard to the prevention and remedying of environmental damage (Environmental Liability Directive).

44 Directive 2014/52/EU, OJ 2014 L124/1, of the European Parliament and of the Council of 16 April 2014 amending Directive 2011/92/EU on the assessment of the effects of certain public and private projects on the environment (Impact Assessment Directive).

45 Council Directive 92/43/EEC, OJ 1992 L206/7, of 21 May 1992 on the conservation of natural habitats and of wild fauna and flora (The Habitats Directive).

46 Directive 94/22/EC, OJ 1994 L164/3, of the European Parliament and of the Council of 30 May 1994 on the conditions for granting and using authorizations for the prospection, exploration and production of hydrocarbons.

47 Ibid, Article 6(2). See also Finn Arnesen, "The Adoption of the Production Licence Directive", in Peter-Christian Müller-Graff, Erling Selvig (eds) The European Economic Area -Norway's Basic Status in the Legal Construction of Europe, Berlin Verlag, Tano Aschehoug, 1997, pp. 81-96. 
system of Member States (endorsed in the Directive) is one of the tools to give effect to the preventive measures and the Directive is closely linked to the Offshore Safety Directive and other relevant directives.

The timeline of the EU environmental measures in the offshore sector shows that the adoption of the sector-specific measures were significantly speeded up after the Macondo blow out (Deepwater Horizon) in 2009. Such a major accident at an offshore installation is obviously capable of damaging the environment to such a significant extent that, in the absence of sufficiently effective rules, the objective of achieving 'good environmental status' would be seriously compromised. ${ }^{48}$

After the Macondo, in 2012, the EU acceded to the Barcelona Offshore Protocol. ${ }^{49}$ The next step was the adoption of the Offshore Safety Directive (OSD) in 2013..$^{50}$ Both instruments are concerned particularly (but not limited to) with transboundary pollution damage.

The OSD addresses only major offshore accidents and has a general geographic application. The Directive recognizes that major accidents are likely to have devastating and irreversible consequences on the marine and coastal environment. ${ }^{51}$ 'Major environmental incidents' are included in the scope of the Directive only to the extent they result from such incidents and result, or are likely to result, in 'significant adverse' effects on the environment in accordance with the Environmental Liability Directive (ELD).

While the OSD aims at preventing major accidents in the oil and gas sector, or minimizing risks of such accidents, it does not include more subtle but systematic pollution arising from normal offshore operations. A detailed discussion of the issues relating to the EU rules on protection from such pollution is outwith the scope of this chapter. Regular discharges can be addressed through the emissions regulation. ${ }^{52}$ It should be noted in this respect, however, that the two regional instruments mentioned earlier - Barcelona Offshore

48 It should be noted that, while environmental concerns are important, the Offshore Safety Directive is not designed to deal exclusively with the environmental effects of an accident; it includes all aspects including safety of life, health etc.

49 Above $\left(\mathrm{n}_{31}\right)$.

50 Directive 2013/30/EU, OJ 2013 L178/66, of 12 June 2013 on safety of offshore oil and gas operations and amending Directive 2004/35/EC.

51 A 'major' accident is defined in Article 2(1) as a very serious incident in relation to the installations and connected infrastructure.

52 Directive $2010 / 75 / \mathrm{EU}, \mathrm{OJ} 2010 \mathrm{~L} 334 / 17$, on industrial emissions (integrated pollution prevention and control). Only one provision specifically excludes offshore sector (see Article 28). 
Protocol and ospar Convention - contain a framework for addressing pollution in a broader meaning than the osD. ${ }^{53}$

Furthermore, the OSD only applies to oil and gas (hydrocarbon) activities, and thereby excludes activities aimed at exploring and extracting other seabed minerals. ${ }^{54}$ The Directive applies only to activities within the limits of Member State's continental shelf. ${ }^{55}$

The preamble of the OSD expressly confirms the obligation for the EU environmental action to be supported by the high level of protection based on the principles referred to in Article 192 TFEU. ${ }^{56}$ The Directive does not define these principles for the purposes of the offshore sector, but rather gives them practical effect through the provisions envisaging specific obligations for the offshore sector players and authorities. Member States are free to introduce more stringent requirements than those envisaged in the Directive. ${ }^{57}$

The common feature of the EU environmental regulation is the focus on incidents which may cause 'significant adverse' effects to the environment. These are determined in line with the criteria provided for in the Environmental Liability Directive (ELD)..$^{58}$ However, the ELD criteria are open as they do not establish any standards or thresholds above which adverse effects on the environment become significant. Only damage with a proven effect on human health must be always classified as significant damage. ${ }^{59}$

The main rationale for limiting the scope of the OSD to major accidents with serious impact is based on the cost efficiency considerations inherent in the risk prevention and management strategies imposed by the Directive: preventive measures must be practicable and economically feasible, 'suitable' to prevent or limit consequences for human health and for the environment of major accidents in offshore oil and gas operations. ${ }^{60}$ This approach takes into consideration the realities faced by those entities that have the main responsibility for the safety of the offshore operations, i.e. operators.

53 Offshore Protocol regulates pollution within the meaning of UnCLOS Article 208, including wastes and harmful and noxious substances.

54 Article 1(1) and 2(3) of the Directive. Cf. Seveso-III Directive which excludes offshore sector from its application scope: Article 2(2)(f) of Directive 2012/18/EU, OJ 2012 L197/1, of 4 July 2012 on the control of major-accident hazards involving dangerous substances, amending and subsequently repealing Council Directive 96/82/EC.

Article 2(3) of the Offshore Safety Directive.

56 Above Section 1.

57 OSD is a minimum harmonization directive (Article 1 ).

58 See Annex I and Article 2 of ELD.

59 See Annex I.

6o Article 3(1); Recital 26 and Article 3(3); Article 2(6). 
The approach based on 'suitability' criterion reflects the idea of the preventive principle generally: measures to be taken to prevent certain, identifiable risks should be limited by the 'feasibility' threshold. A very high level of environmental protection envisaged may not be feasible to maintain, but it is better to have realistic, workable standards instead of declaratory high ones.

Whereas some risks brought about by the offshore activities are certain and thereby require specific (i.e. 'suitable') measures, it is much more difficult to determine what measures are appropriate to address uncertain, scientifically yet unidentified, risks. It is unclear how much effort one should invest to avoid these unknown risks, but the precautionary principle requires that at least some proportionate efforts are undertaken to this end. At the same time this also means that we need to tolerate some level of uncertainty in the environmental risks if we want to benefit from the natural resources of the seabed.

While admitting that 'risks relating to major offshore accidents are significant', OSD is aimed at risk minimization, not elimination. ${ }^{61}$ OSD introduces the concept of 'acceptable risk' which means that the operators should reduce the risk of a major accident as low as reasonably practicable, to the point where the cost of risk reduction would be grossly disproportionate to the benefits of such reduction. ${ }^{62}$

OSD is important because it imposes quite specific duties on Member States to introduce risk management and prevention requirements in the national laws. The OSD applies the standard of 'best practice' to determine the acceptable risk levels and to the accident prevention systems. ${ }^{63}$ The osD accepts that the concept of a 'best' practice is dynamic and must evolve in the light of new knowledge, invention and technology developments. ${ }^{64}$ An important quality of 'the best' practice for major accident prevention in offshore is the goal-setting approach based on the risk assessment and reliable management system. This will particularly benefit Member States with poorly developed offshore safety culture. ${ }^{65}$

In addition, a Major Hazard Report must be elaborated and kept up-to-date by the operators in order to meet the requirements of osD relating to the preparing and carrying out offshore oil and gas operations. ${ }^{66}$ OSD facilitates the

61 Recital 6. The osD defines risk as 'the combination of the probability of an event and the consequences of that event.' Article 2(4).

62 Article $3(4)$. See also Sadeleer at p. 91 et seq.

63 Article 2(8).

64 Recital 30.

65 The North Sea States are often given as a good example to follow (see Impact Assessment).

66 Article 11(1). 
application of the Environmental Impact Assessment Directive to the offshore sector-specific challenges. ${ }^{67}$

In addition to the operator's own control based on the risk management and emergency response systems (which is also subject to independent verification), OSD requires that these two tasks are performed by different public bodies to ensure that the competent authority controlling offshore operations is independent from the licensing authority. ${ }^{68}$

The main task of the licensing authorities is to make sure that the applicants for such licences are capable of meeting the requirements for the corresponding offshore activities. ${ }^{69}$ The OSD establishes an important connection to Directive 94/22/EC (the Hydrocarbons Directive) clarifying the considerations to be taken into account by the licensing authority when assessing the techni$\mathrm{cal}$ and financial risks of the offshore operations. The licensing authority must consider the operator's ability to ensure 'continued safe and effective operations under all foreseeable conditions. ${ }^{70}$

One of the principles set out in Article 191(2) TFEU is the polluter-pays principle. The principle addresses situations when environmental damage has already been caused. The costs resulting therefrom, including the costs of restoring the environment, must be borne by the polluter. ${ }^{71}$

The polluter-pays principle was incorporated into the EU law in the Environmental Liability Directive (ELD) which establishes the framework of the environmental liability based on the 'polluter-pays' principle, to prevent and remedy environmental damage. OsD refers consistently to the polluterpays principle and to the ELD throughout the preamble and the main text, removing any doubt as to the applicability of environmental liability to damage caused by offshore activities (in the sector specified by OSD and ELD). ${ }^{72}$

The OSD has introduced several important adjustments to the ELD regime, making it stronger to deal with remedial issues in the offshore sector.

$67 \quad$ Recital 5 of the EIA Directive.

68 To strengthen control over offshore activities, the OSD also envisages public participation in the decision-making processes (EIA Directive) and public access to the supervision of offshore operations with potentially significant effects on the environment: see Recitals 15, 16 and Articles 5, 8(4), 9.d and 24.

69 Article 4 (OSD).

70 Article 4(2) specifying the aspects which the authority must take into consideration when making such assessment.

71 See generally, David Langlet and Said Mahmoudi, EU Environmental Law and Policy, oup, 2016, p. 55 .

72 'Environmental damage' includes damage to protected species and habitats and water damage (Article 2(1), but excludes damage caused by pollution of diffuse character (Article 4(5)). 
First, the essential improvement in the liability regime for environmental damage caused by offshore accidents introduced in the OSD is the extension of the territorial scope of liability for water damage under the ELD. This is now brought in line with the definition of 'marine waters' in the Marine Strategy Framework Directive and stretches to the outmost reach of the area where a Member State has and/or exercises jurisdictional rights, in accordance with UNCLOS, namely, the continental shelf. ${ }^{73}$ Considering that offshore operations occur mostly outside territorial sea limits, such an extension was very necessary.

Secondly, OSD ensures that the responsible entity is clearly identifiable and accessible, something which is identified as a problem in the ELD. ${ }^{74}$ With respect to the accessibility, the OSD assigns the main responsibility to the licensee, irrespective of whether operations are carried out by the licensee or, or on behalf of, the licensee or the operator. However, the operator is also assigned a central role and must always be the entity with the primary responsibility for safety of operations, to ensure that the environmental liability regime is functioning properly. ${ }^{75}$

Importantly, Member States must ensure that the licensees are financially capable to remedy the damage caused by an offshore accident. OsD emphasizes in a number of provisions that the ability to provide financial compensation for damage is an essential requirement which Member States must impose on licensees and operators before granting the licence. ${ }^{76}$ As to the licensee's financial ability to remedy the potential or real damage, Member States are required to ensure that the licensee is financially liable for the prevention and remediation of environmental damage, caused by offshore oil and gas operations.

Thus the OSD contributes to a more adequate and comprehensive mechanism for the application of the polluter-pays principle in the offshore sector. However, ELD and consequently OSD apply only to pure ecological damage and do not regulate the civil liability or affect rights of compensation for traditional damage granted under any relevant international agreement regulating

73 Article 7(1)(b)(ii) OSD and Article 3(1)(a) of Directive 2008/56/EC cited in fn. 41. Before the OSD was adopted, a significant 'limitation had followed from the restricted definition of 'water damage' of Directive 2000/60/EC, OJ 2000 L327/1, (Water Damage Directive) applicable only to territorial waters within 12 nautical miles. This definition excluded the larger areas of the continental shelf with most offshore activities.

74 Also C-188/07 Mesquer [2008] ECR I-4501 (holders or previous holders of waste).

75 Article 2(5) and Article 3(2) and Recital 13 OSD. OsD defines the operator as the entity appointed by the licensee or licensing authority to conduct offshore oil and gas operations, including planning and executing a well operation or managing and controlling the functions of a production installation'. (Note that ELD refers to the 'operator' generally).

76 Article 4(3). 
civil liability. ${ }^{77}$ So, by contrast to shipping, where there exist liability mechanisms allowing for financial compensation for damage caused by the pollution from ships, no equivalent mechanisms at the EU (or international) level exist for pollution damage resulting from offshore activities.

\section{Conclusions and Challenges Ahead}

There are several general conclusions that are clear as far as the application of EU law to the seabed is concerned. First, EU law applies to the seabed only where EU member States have sovereignty in accordance with international law. Secondly, EU policy papers in respect of seabed mining indicate that the EU clearly intends to play a role in shaping seabed mining as such activity is perceived as economically important for the EU market. Thirdly, even though several EU environmental legislative measures may be applied to seabed activities, uncertainty remains as to whether it is the EU, the EU Member States, or both that have responsibility for environment protection given that the EU Member States have individually assumed obligations under international law. Finally, although general principles of environmental protection are embedded in international law, the EU provides more precise context and has an effective enforcement mechanism to ensure adherence by the EU Member States.

As far as the application of EU law is concerned, it is submitted that in the context of the EEA, EEA law applies only to the territory of the parties to that agreement and therefore the position may be different from the one under EU law. Furthermore, it is uncertain whether the EU has competence to adapt measures requiring EU Member States to act, for example, by requiring them to carry out seabed activities or imposing specific conditions as to how EU Member States decide to exploit the seabed over which they have international sovereignty. Nevertheless, should coastal EU Member States adopt national legislative measures which may give rise to different national standards, then the challenge for the $\mathrm{EU}$ is to decide whether the risk to the internal market warrants legislation to be adopted under Article 114 TFEU on the basis of necessity to safeguard the integrity of the internal market.

77 ELD also excludes personal injury, damage to private property or to any economic loss; it does not affect any right regarding these types of damages and it does not give private parties a right to compensation as a consequence of environmental damage or of an imminent threat of such damage (Article 3(3)). 
As to the regulation of seabed mining activities, the EU considers that international institutions have not delivered and that it is well paced to play a significant role in management of the seabed. Already, where EU Member States have jurisdiction to regulate seabed mining activities under the UNCLOS regime, general principles of EU law apply ${ }^{78}$ and general EU rules adopted to regulate the activities of market operators, such as reporting obligations imposed on undertakings, will be applied equally to operators seeking mining licences. A problematic scenario may arise if the EU decides not to wait for the international community to act and adopts specific legislation to regulate seabed mining activities carried out within the jurisdiction of the EU Member States. Should such a situation arise, then there is a great risk that the EU may adopt its own standards for seabed mining operations ahead of the international regime..$^{79}$ The challenges will then be to establish an international regime, as well as to ensure that one regime prevails.

Similarly, as far as environmental protection of the seabed is concerned, there are clearly gaps and inconsistencies which the EU, irrespective of whether its competence is exclusive or shared, is willing to act and impose a minimum standard of safety in all activities in the offshore sector. The osD has strengthened ELD in the oil and gas sector but it would be an advantage for some further action in respect of compensation and risk pooling arrangements as suggested in Recital 63 of the osD.

There is no doubt that disposal and management of waste produced as a result of exploration and extraction of minerals of the seabed as well as dumping of de-commissioned installations, is a serious challenge. A comprehensive framework for the safe management of waste from extractive industries at EU level is laid down in the 2006 Mining Waste Directive. ${ }^{80}$ However, waste resulting from the offshore prospecting, extraction and treatment of mineral resources is excluded from the scope of this Directive. ${ }^{81}$ To the extent of this

${ }_{7} 8$ E.g. the principle of no discrimination on the grounds of nationality, origin and destination.

79 A similar situation arose in 2003 concerning the thickness of the hull of oil tankers. The slowness of the international IMO regime to take a decision to amend MARPOL (International Convention on Prevention of Pollution from Ship) and phase-in double hull oil tankers, led the EU to take unilateral action and adopt Regulation 1726/2003, OJ 2003 L249/1, of the European Parliament and of the Council of 22 July 2003 amending Regulation 417/2002/EC on accelerated phasing-in of double hull oil tankers. At the end of 2003, IMO took the decision to amend MARPOL.

8o Directive 2006/21/EC, OJ 2006 L102/15, of the European Parliament and of the Council of 15 March 2006 on the management of waste from extractive industries and amending Directive 2004/35/EC.

81 Ibid, Article 2(2)(b). 
exclusion, the general Waste Directive applies to waste produced on offshore installations and brought on shore, ${ }^{82}$ leaving the operator with the responsibility to have the waste treated properly in accordance with the requirements of the Directive.

It seems fair to conclude the endeavours of the EU with regard to seabed mining in many respects resembles a voyage into unchartered waters, and that it is called for the vigilance required when sailing in such waters.

82 By virtue of Article 2(2)(d) of Directive 2008/98/EC of the European Parliament and of the Council of 19 November 2008 on waste (Waste Framework Directive). 